\title{
SÍNTESE DE GRANDES FERIDAS DA PAREDE CORPÓREA COM TIRA ELÁSTICA DE BORRACHA
}

\author{
Synthesis of large wounds of the body wall with rubber elastic band
}

\author{
Andy PETROIANU
}

DESCRITORES - Ferida. Borracha. Terapêutica.

Correspondência:

Andy Petroianu,

e-mail: petroian@gmail.com

Fonte de financiamento: não há

Conflito de interesses: não há

Recebido para publicação: 04/08/2009

Aceito para publicação: 28/02/2010

HEADINGS - Wound. Rubber. Therapeutics.
RESUMO - Racional - As grandes feridas da parede corpórea, decorrentes de traumas extensos, retirada de tumores ou laparostomias prolongadas constituem um desafio cirúrgico de difícil solução. Objetivo - Mostrar a eficácia da aproximação das bordas de grandes feridas, utilizando tira elástica de borracha. Método - Uma ou duas tiras elásticas de borracha (gominha circular) foram suturadas sob tensão moderada às bordas opostas de 21 grandes feridas, em diversas localizações corpóreas. Essas tiras eram substituídas, quando rompiam, ou refixadas, quando perdiam a tensão, até obter-se a aproximação completa das bordas das feridas. Resultado - Em todos os casos houve o fechamento completo das feridas, sem outro procedimento ou artifício auxiliar.Não ocorreu complicação maior decorrente desse tratamento. Conclusão - A síntese de grandes feridas corpóreas com tiras de borracha mantidas sob tensão moderada é uma alternativa simples, eficaz e de custo baixo, que pode ser utilizada em muitas circunstâncias cirúrgicas.

ABSTRACT - Background - The large wounds of the body wall, due to traumas, removal of tumors or prolonged laparostomies are a difficult surgical challenge with complex treatment. Aim - Presents the efficacy of the closure of large surgical wounds using rubber elastic bands. Method - One or two circular rubber elastic bands were sutured under mean tension at the opposite edges of 21 large wounds located in different body sites. These rubber strips were replaced when they were broken or refixed when they have lost their tension until the complete closure of the wounds. Results - Complete closure of the wounds was achieved in all cases without any other surgical procedure or device. No major complication due to this treatment was verified. Conclusion - The synthesis of large wounds with rubber elastic bands kept under mean tension is a simple, efficacious and unexpensive surgical option that may be useful for treatment in several circumstances.

\section{INTRODUÇÃO}

U $m$ dos maiores desafios cirúrgicos é o fechamento de grandes feridas, decorrentes de traumas maiores, retirada de tumores extensos ou procedimentos cirúrgicos, que deixam as bordas das feridas afastadas por tempo prolongado, como as laparostomias ${ }^{4,5}$. Nessas situações, os retalhos de pele (diretos, ou com a utilização de vetores, ou após expansores cutâneos) e os musculocutâneos, são as alternativas cirúrgicas mais utilizadas com resultados, por vezes, insatisfatórios, mesmo quando realizados por cirurgiões plásticos experientes ${ }^{2,6}$. Outra opção é manter a ferida com curativo, até granular e cobri-la, em seguida, com enxerto de pele parcial ou total. Há ainda a possibilidade de cuidar da ferida até a aproximação espontânea das bordas ou sua cobertura natural por tecido fibroso. Para acelerar a aproximação das bordas de grandes feridas, têm sido propostas suturas progressivas ou a utilização de cintas, fitas adesivas e pesos ${ }^{3,8,12}$.

O objetivo desta publicação é apresentar a experiência do autor com uma alternativa eficaz, simples e barata, para aproximar as bordas da ferida, por meio de tira elástica de borracha, suturada às bordas da ferida. 
MÉTODO

A experiência consiste de 21 grandes feridas, decorrentes da retirada de extensos tumores de parede abdominal (três casos) (Figuras 1A e 1B), remoção de úlceras de Marjolin (dois casos), feridas remanescentes de infecções graves de partes moles (quatro casos) (Figuras $1 C$ e 1D), e aberturas abdominais remanescentes de laparostomias (nove casos) (Figura $1 \mathrm{E})$ e grandes feridas consequentes à necroses extensas de úlceras de decúbito (três feridas em um paciente) (Figura 1F). Todos os tratamentos foram realizados em pacientes adultos (23 a 74 anos), de ambos os sexos (13 homens e 6 mulheres).

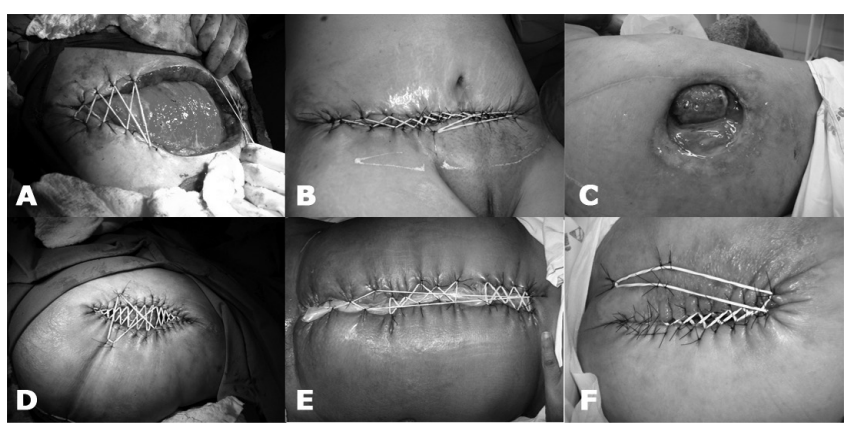

FIGURA 1 - Utilização de tiras elásticas de borracha para tratar grandes feridas da parede corpórea. A - Ferida da parede hipogástrica após a retirada de um grande sarcoma, sendo fechada com tira elástica de borracha. B - Aspecto da ferida após 28 dias da operação. C - Abertura da parede da região coxofemoral após infecção e destruição dos tecidos moles, no pós-operatório de implante de prótese de cabeça de fêmur. D - Aspecto da ferida logo após o término da operação. E - Síntese de grande úlcera de decúbito na região coccígea com tira elástica de borracha. F - Fechamento de laparostomia, com tiras elásticas de borracha, sobre "tela de Bogotá", para proteger as vísceras abdominais. Em seguida, a tela será retirada através dos pontos dessa tira

A aproximação das bordas opostas dessas feridas foi obtida por meio de tira circular elástica de borracha, conhecida como elástico ou gominha, que, entre outras funções, é habitualmente utilizada para conter maços de dinheiro em banco. Essas gominhas foram esterilizadas em autoclave.

Após a limpeza demorada das feridas com solução anti-séptica, suas bordas foram anestesiadas com lidocaína. Uma tira de borracha circular era suturada às bordas da ferida com fio de náilon 2-0. Iniciava-se a sutura com um ponto que englobava a gominha e um dos vértices da ferida. Em seguida, esse elástico era dobrado sobre si, para formar um $\mathrm{X}$ e cada lado dele era fixado com ponto às bordas da ferida. Essa tira de borracha foi consecutivamente dobrada em X outros pontos fixaramna às bordas da ferida, até atingir-se o outro vértice. Os pontos da pele eram passados paralelamente à ferida, a cerca de um centímetro da borda, para evitar que o fio cortasse o tecido, pela tração do elástico.

Nos casos em que a ferida foi maior do que uma única gominha podia aproximar, uma segunda gominha complementou o procedimento (Figura 1). Na experiência apresentada neste trabalho, não houve a necessidade de utilizar mais de dois elásticos de borracha.

Em curto período de tempo, houve a aproximação das bordas da ferida e, consequentemente, o elástico afrouxava e perdia sua tensão de tração. Nessa situação, sob anestesia local, a tira de borracha era tracionada entre os pontos, e dados novos pontos, para mantê-la com a tensão moderada. Durante esse procedimento, a segunda gominha, quando presente, era retirada. Nos casos em que o elástico se rompia, ele era substituído por outro novo e o procedimento era repetido.

As feridas receberam os cuidados diários habituais de limpeza com solução salina e proteção. Nos casos em que houve infecção local, seu tratamento consistiu de introdução de açúcar na ferida, duas vezes por dia e sua limpeza com solução salina.

\section{RESULTADOS}

Em todos os 19 doentes, as feridas foram aproximadas muito satisfatoriamente. No início, alguns pacientes reclamaram de dor, que era resolvida com analgesia comum, porém, em poucos dias, já não havia mais a necessidade de medicação. Os curativos simples foram suficientes para proteger as feridas.

O fechamento completo ocorreu em prazos que variaram entre um e 34 dias. Após a aproximação completa das bordas, a pele foi suturada com pontos separados de fio de náilon 3-0 em 15 pacientes. A gominha foi retirada um dia após a sutura da pele ou, nos três casos sem sutura, logo após a síntese completa das bordas. Nesse dia todos os pacientes receberam a alta hospitalar. Os pontos de pele foram retirados após três semanas.

As complicações mais comuns foram infecções locais, tratadas com limpeza local, duas a três vezes por dia, e cobertura da ferida com açúcar. Não houve a necessidade de antibioticoterapia. Todos os doentes com queixa de desconforto ou dor local nos primeiros dias pós-operatórios receberam analgésicos comuns, à base de dipirona. Apenas essa medicação foi suficiente para controlar a dor.

Todos os pacientes ficaram satisfeitos com o resultado obtido e nenhum deles solicitou correção plástica posterior, apesar de a maior parte das cicatrizes ter ficado alargada e com as marcas dos pontos laterais.

\section{DISCUSSÃO}

Apesar de a tira elástica de borracha não ser um recurso novo ou original na prática cirúrgica, não se conseguiu encontrar publicação relativa ao 
seu uso para a aproximação das bordas de feridas extensas. Previamente, esse procedimento foi utilizado para tratamento de síndrome compartimental de membro superior, aproximando as aponeuroses com tiras elásticas de borracha ${ }^{10}$. Em outro trabalho, fitas de borracha auxiliaram na aproximação de feridas ortopédicas decorrentes de fraturas abertas ${ }^{7}$. Os demais artigos da literatura mencionam fitas elásticas de borracha apenas para manter a tensão de curativos compressivos sobre enxertos de pele (tie-over) $)^{1,9,11}$. Esse é um recurso simples e de grande valia em situações cirúrgicas de solução trabalhosa. Os excelentes resultados obtidos nos pacientes desta casuística estimularam a presente apresentação.

Este artigo teve por objetivo apresentar uma experiência cirúrgica de acompanhamento de doentes tratados pelo autor com sucesso em situações de desafio grande para seu reparo e com difícil opção para outras reconstruções. O objetivo era apresentar a técnica, sua factibilidade e os bons resultados obtidos. Por não ser uma pesquisa, mas uma aplicação terapêutica de um método já descrito na literatura em outras situações ${ }^{10}$, não houve seu registro em Comitê de Ética.

Tecnicamente, a aproximação das bordas com essa gominha é factível a todo cirurgião, mesmo aquele com pouca experiência. Essas tiras de borracha não têm custo quase algum e são disponíveis com grande facilidade. A maior atenção que se deve ter é com a tração moderada da gominha, para permitir tensão contínua sobre a pele, sem lesá-la pelo trauma do ponto que a transfixa. Quanto aos demais cuidados com a ferida, eles não excedem à rotina de limpeza e proteção adequadas.

A sutura da pele, após a aproximação das bordas pode ser dispensada, pois a união cutânea promove a cicatriz. No entanto, com os pontos adequadamente transpassados, evita-se a inversão da pele e o resultado estético é melhor.

\section{CONCLUSÃO}

A tira elástica de borracha circular (gominha) é um recurso eficaz, de fácil utilização, barato e muito disponível, que deve ser considerado para tratamento de grandes feridas da parede corpórea.

\section{REFERÊNCIAS}

1. Cheng LF, Lee JT, Chou TD, Chiu TF, Sun TB, Wang CH, Chien SH, Wang HJ. Experience with elastic rubber bands for the tie-over dressing in skin graft. Burns 2006; 32: 212-215.

2. Cipolla J, Stawicki SP, Hoff WS, McQuay N, Hoey BA, Wainwright G, Grossman MD. A proposed algorithm for managing the open abdomen. Am Surg 2005; 71: 202-207.

3. Fansler RF, Taheri P, Cullinane C. Polypropylene mesh closure of the complicated abdominal wound. Am J Surg. 1995;170:15-18.

4. Howdieshell TR, Proctor CD, Sternberg E, Cué JI, Mondy JS, Hawkins ML. Temporary abdominal closure followed by definitive abdominal wall reconstruction of the open abdomen. Am J Surg 2004; 188: 301-306.

5. Jermigan TW, Fabian TC, Croce MA, Moore N, Pritchard FE, Minard G, Bee TK. Staged management of giant abdominal wall defects. Ann Surg 2003; 238: 349-357.

6. Miller PR, Thompson JT, Faler BJ, Meredith JW, Chang MC.. Late fascial closure in lieu of ventral hernia. J Trauma 2002; 53: 843-849.

7. Mosheiff R, Segal $D$, Liebergall M. The rubber band technique. Am J Orthop 1999; 28: 666-667.

8. Petersson U, Acosta S, Björck M. Vacuum-assisted wound closure and mesh-mediated fascial tract open abdomen. World J Surg 2007; 31: 2133-2137.

9. Prunes $F$, Asbun $H$. A simplified stent dressing technique using elastic rubber bands. Ann Plast Surg 1989; 23: 84-85.

10. Raskin KB. Acute vascular injuries of the upper extremity. In Shaw Wilgis EF (ed). Vascular disorders. Hand Clinics 1993; 9: 115-130.

11. Rees TD. Use of rubber bands in tie-over dressings on the chest wall. Plast Reconst Surg 1969; 43: 635-636.

12. Weinberg JA, George RL, Griffin RL, Stewart AH, Reiff DA, Kerby JD, Melton SM, Rue LW 3rd.Closing the open abdomen: improved success with Wittmann Patch staged abdominal closure.J Trauma. 2008; 65: 345-348. 